Discussion Paper No. 725

\title{
CAPITAL INFLOW INTO DEVELOPING ECONOMIES: \\ A MACROECONOMIC STUDY
}

\author{
Soumyen Sikdar
}

November 2008

The Institute of Social and Economic Research Osaka University

6-1 Mihogaoka, Ibaraki, Osaka 567-0047, Japan 


\title{
CAPITAL INFLOW INTO DEVELOPING ECONOMIES: A MACROECONOMIC
} STUDY

\author{
Soumyen Sikdar
}

\begin{abstract}
External capital inflow on a massive scale into the emerging market economies is a very significant phenomenon of recent years. Making distinctions between direct investment, real and financial, and portfolio investment and incorporating crowding in or crowding out effects we derive some results about the impact of higher inflow on output, investment and the exchange rare. A formula is suggested for estimating the cost of central bank intervention.
\end{abstract}

JEL Code: E12, F32, F41

Key words: Foreign direct investment, Foreign portfolio investment, Foreign reserves, Flexible exchange rate.

Author Affiliation: Department of Economics, University of Calcutta, Calcutta, India. 


\section{Introduction}

Over the past two decades the international economy has witnessed a dramatic upsurge in the flow of private funds to the emerging market economies of Asia and Latin America. India, in particular, has become a very attractive destination. Several factors have contributed towards this outcome. Most notable among them are political stability, strong commitment to economic reform with emphasis on rupee convertibility, low inflation rate (an indicator of good monetary management) and a healthy prospect of sustained growth in the foreseeable future. This has been a very significant development for the Indian economy which was virtually closed to international capital movements up to the early 1990s, when the programme of structural reforms was first initiated.

On the exchange rate front India has moved from very strict control to a regime of carefully managed float. For the most part over the last decade this has taken the form of preventing currency appreciation in the face of burgeoning inflow of funds. The Reserve Bank of India's ( RBI) stock of foreign reserves has grown by leaps and bounds as a consequence. Currently it stands above USD 300 billion. To neutralize the monetary effects of dollar purchase, RBI has to undertake sterilization on a big scale. This has entailed large quasi fiscal costs (approximately 1.2 per cent of GDP), because domestic interest rates exceed the rate on US Treasury Bills in which the funds are mostly invested.(China has a much bigger stock of reserves, but she makes a huge profit out of her foreign exchange operations by selling securities at a rate lower than the rate on dollar bonds.) Critics of RBI maintain that the policy of intervention has been very costly for the economy by locking up huge investible funds in the form of sterile dollar reserves and by preventing a decline in the domestic interest rate. This is one of the issues that will be addressed in the present paper. We shall analytically derive an expression for the growth rate of national income in a situation where the exchange rate is completely flexible (no intervention by RBI and hence no accumulation of reserves and sterilization). By comparing this hypothetical growth rate with the actual growth rate the cost, if any, of intervention in terms of forgone growth may be quantified.

In sharp contrast to China capital inflow in India ( henceforth, the term "capital inflow" will always stand for "net capital inflow") is dominated by foreign portfolio investment (FPI) by foreign institutional investors (FII), rather than foreign direct investment (FDI). Also, this FPI is mostly in equities of well known Indian companies rather than bonds. Equity investment by FIIs as a proportion of total FPI exceeded 70 per cent in 2000-01 and remained close to that thereafter( RBI reports). Given the beneficial nature of FDI the low share is a matter of concern. To make matters worse, there is reason to believe that a significant portion of incoming FDI is financial rather than real in nature. Real FDI directly adds to the capital stock and entails positive external effects through diffusion of knowledge. Financial investment is less productive, consisting mainly of expenditure incurred to acquire ownership of existing assets. According to one estimate ( Kumar, 2000), over 1997-2000 approximately 40 per cent of FDI was devoted to M\&A of existing Indian enterprises. Our analysis makes a distinction between real (contributing to capital formation in the current period) and purely financial FDI. 
The effect of incoming foreign investment on domestic investment has been the subject of some debate. There is empirical support for crowding in as well as for crowding out. In the case of crowding in ( foreign investment stimulating local investment) the beneficial impact of FDI is magnified. Much will depend on the nature of foreign investment. Investment in infrastructure and other complementary factors is likely to stimulate local investors, whereas setting up a plant to compete in the local market will have an opposite effect. In the input market arrival of foreign producers tends to impart an upward push to the prices of inelastically supplied factors of production, particularly of skilled labour and this has a negative effect on the profitability of local firms. For India there is no clear evidence either way. Our model keeps the sign open for the crowding effect and notes the consequences in particular contexts.

Some comments on the analytical framework are in order at this point.The paper uses the standard Mundell Fleming apparatus to address some issues related to greater capital inflow into a developing economy. A few words in justification of the framework may be needed. According to one influential school of economists macro models must be strictly micro-founded to be worthy of attention. We do not support this extreme view. The ultimate test is the ability to advance one's understanding of real world phenomenon. The Mundell Fleming framework that starts from "ad hoc" behavioural equations has passed this test with flying colours. At this point let us listen to what Paul Krugman has to say on this issue. "For many purposes ad hoc models are as good or better than the carefully specified, maximizing intertemporal model ---One of the influential macro models of the 1990s, and deservedly so, is the revisitation of Mundell-Fleming-Dornbusch by Obstfeld and Rogoff. It's a beautiful piece of work, integrating a new Keynesian approach to price stickiness ( albeit with the ad hoc assumption that prices are set for only one period) with a full intertemporal approach to aggregate demand.----But is this model actually any better at predicting the impact of shocks in the real world than a three or four equation, back of the envelope, Mundell-Fleming model? The authors give no reason to think so." (Krugman, 2000) Also, it is well known that for the sake of tractability optimization based models often have to make extremely simplifying assumptions. Methodological fatwas are as unlikely to advance the cause of progress in economic analysis as in any other field of human endeavour.

The remainder of the paper is organized in six sections. Section 2 sets out the basic model. In the next section the analytical distinctions between two types of FDI and between FDI and FPI are spelt out and the main propositions are established. Crowding in or crowding out plays an important role. The impact of a rise in expected inflation is analyzed. Section 4 provides a convenient formula for estimating the costs in terms of forgone growth of policy intervention by the central bank. The next section shows that some of the results of the previous section may be modified if the consumer price index, rather than the producer price index, is used in formulating equilibrium in the money market. In Section 6 the analysis is extended to incorporate two types of expectations on the part of the investors, regressive and perfect foresight. In the latter case steady state solutions under simple dynamics are compared to evaluate the impact of changes in the inflow of FPI. Concluding remarks are presented in the final section. 


\section{The model}

The country is completely specialized in the production of a commodity which is domestically consumed and exported. Its price $\mathrm{P}$ is fixed in the domestic currency. It imports a commodity the price of which $\mathrm{P}^{*}$ is fixed in the foreign currency. Only two countries are assumed to keep the exposition simple and manageable. Commodity prices are fixed, possibly due to the existence of excess capacity and fixed money wages, but the exchange rate is not fixed. Since commodity prices are fixed, the nominal and the real exchange rates are perfectly correlated. We ignore the government for convenience.

The following symbols will be used in the discussion that follows: Y : GDP, S: saving, I: investment, NX: net exports, NCI : net capital inflow, $r$ : rate of interest, $\mathrm{M}$ : money supply, e : exchange rate (= domestic currency / foreign currency)

The basic structure of the model is described by the following equations:

(1) IS : $\mathrm{S}=\mathrm{I}+\mathrm{NX}$

(2) BP: NX+ NCI $=0$

The first ( the open economy IS equation) says that saving should equal investment plus net exports, the second (the balance of payment or BP equation) is the condition for equilibrium in the balance of payments $(\mathrm{BoP})$ under a fully flexible exchange rate (no intervention by the RBI). If (2) holds, the market for foreign currency is in balance because (-NX), the current account deficit, is the demand for foreign exchange and NCI is the supply. It is to be noted that NCI is real flow in units of the home good.

Linear functional forms with positive coefficients are posited for convenience. The functions are:

(i) $\mathrm{S}=\mathrm{s} \mathrm{Y}$

(ii) $\mathrm{I}=\mathrm{I}_{0}-$ ir

(iii) $\mathrm{NX}=\mathrm{X}_{0}+$ he $-\mathrm{mY}$

(iv) $\mathrm{NCI}=\mathrm{F}$

(v) $\mathrm{r}=\mathrm{kY}-\mathrm{gM}$

$(\mathrm{s}, \mathrm{i}, \mathrm{h}, \mathrm{m}, \mathrm{k}, \mathrm{g})>0$

Net export is taken to be an increasing function of e because an increase in e is a depreciation of the home currency. Net capital inflow is taken to be exogenously fixed at $F$ for the moment. Equation (v) is the standard LM curve, which says that for a given $\mathrm{Y}$, a rise in money supply $\mathrm{M}$ will reduce $\mathrm{r}$.

Solving Equations (1) and (2) it is easy to derive the following comparative static expressions:

$$
\frac{d Y}{d F}<0, \frac{d e}{d F}<0, \frac{d r}{d F}<0
$$


The impact on $\mathrm{Y}$ and e can be graphically represented. By substituting the expression for $\mathrm{r}$ from Equation (v) in Equation (1) we get the following expression involving Y and e:

$$
\mathrm{Y}(\mathrm{s}+\mathrm{ik}+\mathrm{m})=\mathrm{I}+\operatorname{igM}+\mathrm{X}_{0}+\mathrm{he}
$$

In Figure 1 this is drawn as the ISLM curve. Equation (2) in conjunction with (iv) gives the BP curve. Though both are upward sloping BP is flatter than ISLM. A ceteris paribus rise in $F$ shifts $B P$ to the right, causing equilibrium to move from $E_{1}$ to $E_{2}$. Both $Y$ and e are lower in the new situation.

So an exogenous rise in capital inflow leads to a decrease in GDP, decrease in e ( currency appreciation) and a decrease in $r$. This we designate the standard result( Rakshit, 2003). Investment is stimulated by the fall in the rate of interest. Although current GDP contracts, future capital stock is boosted. Contraction of income is explained by the fact that rise in F implies a lower NX ( Equation 2) and NX is a component of aggregate demand. Downward adjustments in $\mathrm{Y}$ and e ensure that Equation (2) is restored through a fall in NX following the rise in F. However, the beneficial impact on investment may be offset if I also depends positively on Y. In that more general case the effect on future capital stock is ambiguous.

\section{Distinction between FDI and FPI}

The previous section made no distinction between FDI and FPI, a distinction that is important in reality. The difference we want to stress here is that FDI contributes directly to real investment in the current period whereas FPI does not. But we also recognize that a portion of the capital inflow that is officially designated FDI is really financial in nature ( going into acquisition of existing assets and managerial control through M\&A ) and do not contribute to current investment in the real sense. As noted in the Introduction, financial investment accounts for a significant proportion of FDI into India. We assume that a fraction $t_{1}$ of FDI is real in nature and the rest is financial.

Real FDI has important external effects on domestic investment. It may play a complementary role( crowding in effect) or a competitive role( crowding out effect).We incorporate this into our analysis by assuming that one unit of FDI stimulates $t_{2}$ units of domestic investment in the current period. If $t_{2}$ is positive there is crowding in and $t_{2}$ negative implies crowding out.

Since in our scheme FPI does not add directly to aggregate demand the analysis of the previous section applies without any modification and the standard results remain the same: output contracts, currency appreciates and the rate of interest declines after an increase in autonomous FPI.

Case of FDI

In a situation where the country receives FDI ( real plus financial) of autonomously fixed amount F but there is no FPI, Equation (1) takes the form:

(3) $\mathrm{sY}=\mathrm{I} 0-\mathrm{ir}+\left(\mathrm{t}_{1}+\mathrm{t}_{2}\right) \mathrm{F}+\mathrm{X}_{0}+$ he $-\mathrm{mY}$ 


$$
=\mathrm{I}_{0}-\mathrm{ir}+\mathrm{tF}+\mathrm{X}_{0}+\text { he }-\mathrm{mY} \text {, writing } \mathrm{t}=\mathrm{t}_{1}+\mathrm{t}_{2}
$$

Equation (2) for BoP remains the same. It should be remembered that $t$ can take any value because $t_{1}$ is a fraction but $t_{2}$, ( the crowding effect coefficient) can take any value, positive or negative. Using (v) to eliminate $r$, we can solve for the equilibrium values of $\mathrm{Y}$ and $\mathrm{e}$. The effects of a rise in $\mathrm{F}$ are encapsulated in:

$$
\frac{d Y}{d F}=\frac{t-1}{s+i k}, \frac{d e}{d F}=\frac{m(t-1)-(s+i k)}{h(s+m+i k)}
$$

We can write the implications as :

\section{Proposition 1:}

After a rise in FDI

(a) GDP will go up if $\mathrm{t}>1$. It will decline if $\mathrm{t}<1$.

(b) Home currency will depreciate if $m(t-1)>(s+i k)$. It will appreciate if the inequality is reversed.

\section{Observations}

Now it is possible to have an expansion of national income. Since $t_{1}$ has a maximum value of unity, for this to happen $t_{2}$ must be positive. That is, domestic investment must be crowded in by foreign investment. If the crowding effect is zero or if there is crowding out of any amount, however small, national income will contract as in the standard case. The chance of positive impact on income becomes higher the higher is $t_{1}$, the share of real investment in total FDI.

Depreciation of the currency in the wake of higher capital inflow becomes a possibility. This may occur because the increase in income may be so large ( the condition that ensures depreciation also ensures income expansion) that the rise in current account deficit ( demand for foreign currency) outweighs the increase in supply through incremental FDI. Generally, income may rise accompanied by appreciation or depreciation, but if income falls it must be a case of appreciation.

What about the impact on investment? Given a fixed money supply, if income rises the rate of interest will rise and this will tend to depress investment. But it can be shown that the direct positive effect of higher FDI on investment will always outweigh this induced negative effect. (If I is positively influenced by $\mathrm{Y}$, the positive effect is reinforced.)

$$
\frac{d I}{d F}=\frac{s t+i k}{s+i k}>0
$$

Returning to the case of FPI, we can make it responsive to the interest differential between the two countries. Let the function be, $F=F_{0}+f\left(r-r^{*}\right), f>0$, where $r^{*}$, the 
interest rate in the foreign country, is taken to be exogenously given. It is easy to verify that the old results continue to hold. As $\mathrm{F}_{0}$ increases, $\mathrm{Y}$, e and $\mathrm{r}$ all three go down. Investment is stimulated, or subjected to two opposing pulls if it is positively related to Y.

\section{Impact of macroeconomic stability}

We capture this by introducing the parameter $p^{\mathrm{e}}$, the expected rate of inflation. In the literature this is often taken to be a proxy for the macroeconomic stability of an economy. Now I depends on the ex ante real interest rate, $\left(r-p^{e}\right)$. It is reasonable to take capital inflow to be adversely affected by an increase in expected inflation. Countries suffering from chronic inflation usually experience capital flight. Writing the new investment function as $\mathrm{I}=\mathrm{I} 0-\mathrm{i}\left(\mathrm{r}-\mathrm{p}^{\mathrm{e}}\right)$, it is clear that an increase in $\mathrm{p}^{\mathrm{e}}$ shifts the IS curve to the right and exerts an upward pull on $\mathrm{Y}$. The magnitude of the shift is determined by the magnitude of $i$.

If capital inflow is purely FPI, rise in expected inflation gives additional boost to Y by reducing F.( $\mathrm{Y}$ and $\mathrm{F}$ are inversely related.) So, in this case the effect on national income is unambiguously positive. This is a common feature of short run demand driven models. Given a LM curve that is upward sloping ( not vertical), the rise in the nominal rate of interest is less than the increase in expected inflation and the real rate of interest declines. This boosts investment and output. (a) $\mathrm{t}<1$

In the case of FDI, two subcases may be considered, depending on the value of $t$.

Here, $\mathrm{Y}$ rises as $\mathrm{F}$ falls as in the case of FPI. This reinforces the boost in $\mathrm{Y}$ given by the shifting IS curve.

(b) $t>1$

Here, since $\mathrm{Y}$ and $\mathrm{F}$ move in the same direction, there are opposing pulls on $\mathrm{Y}$. The upward pull will be strong if $i$ is high. The downward pull will be strong if $F$ is very sensitive to pe and $t$ is high.

\section{Growth cost of foreign reserves}

To support the exchange rate of the rupee in the face of ever increasing inflow of funds the RBI has been buying up foreign exchange, especially dollar, from the market on a massive scale. The huge stock is invested mostly in US Treasury Bills which yield fairly 
low returns, but are very liquid. Apart from a desire to protect domestic exporters from currency appreciation, the precautionary motive is at work behind this decision of the Bank. Since most of the inflow is portfolio type with a bad reputation for volatility, maintaining enough reserves is considered a good strategy to ward off potential flight of hot money out of the country. But the policy has been criticized as very costly, because it locks up investible funds in a low paying asset. The framework developed here enables us to make an estimate of the cost, if any, in terms of forgone growth. Expected inflation, assumed to be constant, is suppressed.

Equation (2),(3) along with (iv) and (v) give the following expression for equilibrium GDP:

$$
\mathrm{Y}(\mathrm{s}+\mathrm{ik})=\mathrm{I}_{0}+\mathrm{igM}+(\mathrm{t}-1) \mathrm{F}
$$

Or, $\mathrm{Y}=\alpha_{1} \mathrm{I}_{0}+\alpha_{2} \mathrm{M}+\alpha_{3} \mathrm{~F}$ where the $\alpha$ 's are functions of s,i, $\mathrm{k}, \mathrm{g}$ and $\mathrm{t}$

Or, in terms of growth rates ( subscript $g$ indicating the rate of growth of a variable)

$$
\mathrm{Y}_{\mathrm{g}}=\alpha_{1}\left(\mathrm{I}_{0} / \mathrm{Y}\right) \mathrm{I}_{\mathrm{g}}+\alpha_{2}(\mathrm{M} / \mathrm{Y}) \mathrm{M}_{\mathrm{g}}+\alpha_{3}(\mathrm{~F} / \mathrm{Y}) \mathrm{F}_{\mathrm{g}}
$$

The growth rate $\mathrm{Y}_{\mathrm{g}}$ given by this equation is derived under the assumption of complete flexibility in the exchange rate or no intervention by the RBI. Armed with estimates of the $\alpha$ 's and knowledge of the shares of autonomous investment, money supply and net capital inflow the value of $Y_{g}$ can be obtained. This hypothetical rate may then be compared with the actual growth rate attained under intervention over a given period to get an idea about the magnitude of the growth cost of the policy pursued.

\section{The consumer price index as deflator}

So far we have kept the domestic price level $\mathrm{P}$ fixed and also implicitly assumed nominal money demand to depend on P only. However, in an economy where both the domestic and the foreign goods are consumed a more appealing procedure might be to use a consumer price index (CPI) that gives weight to both goods. If we use this to define nominal money demand or, equivalently, to deflate nominal money supply to arrive at the supply of real balances, some of our results are modified. In particular, a boost in autonomous portfolio investment may stimulate output in the current period. The reason is that with the use of CPI a link is established between the exchange rate and the rate of interest through the money market. FPI lowers the interest rate by boosting the real money supply through currency appreciation.

Let the CPI be written as:

$$
\mathrm{P}_{\mathrm{c}}=\theta(\mathrm{eP} *)+(1-\theta) \mathrm{P}, 0<\theta<1
$$

The weight $\theta$ may be set equal to the share of imports in consumption. Under our assumption $\mathrm{P}, \mathrm{P}^{*}$ are fixed, but since $\mathrm{e}$ is free to vary $\mathrm{P}_{\mathrm{c}}$ will vary with $\mathrm{e}$. A depreciation ( higher e) will raise the CPI by making imports more expensive. An appreciation ( fall in e) will have the opposite effect. If the CPI is used as the appropriate deflator in the money market depreciation (appreciation) of home currency will lead to a rise (fall) in the interest 
rate by reducing ( increasing) the supply of real balances. Thus, other things equal, e and $r$ move in the same direction. The modified LM curve is represented by:

(vi) $\mathrm{r}=\mathrm{kY}-\mathrm{gM}+\mathrm{ue}, \mathrm{u}>0$

The value of the coefficient $\mathrm{u}$ will depend positively on $\theta$, the share of imports in consumption. A large $\theta$ implies that the impact of a given change in e on $\mathrm{P}_{\mathrm{c}}$, and hence on $\mathrm{r}$, is also large.

Replacing (v) by (vi) and doing simple substitution:

$$
\mathrm{Y}(\mathrm{s}+\mathrm{ik}+\mathrm{m})=\mathrm{I}_{0}+\mathrm{igM}+\mathrm{X}_{0}+(\mathrm{h}-\mathrm{iu}) \mathrm{e}
$$

Combining this with the balance of payments equation, we obtain the equilibrium values of $\mathrm{Y}$ and $\mathrm{e}$ and then derive the following:

$$
\frac{d Y}{d F}=\frac{i u-h}{h(s+i k)+i u m}, \frac{d e}{d F}=-\frac{s+i k+m}{h(s+i k)+i u m}
$$

This leads to:

\section{Proposition 2:}

After an increase in FPI

(a) GDP will go up if (iu $-\mathrm{h})>0$ and will go down if $(\mathrm{iu}-\mathrm{h})<0$.

(b) The home currency will appreciate.

It is now possible that higher FPI may boost current national income. The mechanism works through the link between the exchange rate and the rate of interest. High consumption share of imports ( leading to a high $\mathrm{u}$ ) and high $\mathrm{i}$ ( sensitivity of investment to the interest rate) will cause investment to rise significantly following the appreciation of the currency. 
Case of FDI

When it is FDI, rather than FPI, the comparative static results take the form:

$$
\frac{d Y}{d F}=\frac{h(t-1)+i u}{h(s+i k)+i u m}, \frac{d e}{d F}=\frac{m(t-1)-(s+i k)}{h(s+i k)+i u m}
$$

This leads to:

\section{Proposition 3:}

After an increase in FDI

(a) GDP will go up if $\mathrm{t}>1$ - iu / h.

(b) The home currency will depreciate if $\mathrm{m}(\mathrm{t}-1)>\mathrm{s}+\mathrm{ik}$ and appreciate if the inequality is reversed.

The interesting thing is that in this case income expansion is possible after higher inflow even with some crowding out $\left(\mathrm{t}_{2}<0\right)$. The condition for depreciation or appreciation remains the same as in the case when only $\mathrm{P}$ was used as money supply deflator. The impact on the rate of interest is ambiguous. Given the supply of money, it will be higher if income expands and there is depreciation.

\section{Portfolio choice}

So far we have dealt with the consequences of different types of capital inflow, but have not said anything about the asset demand by the investors at home or abroad. This section attempts to do that, albeit in a highly simplified and not entirely satisfactory manner. It is to be noted that the analysis will be restricted to FPI only. The justification is that being essentially long term in nature FDI is driven by long term factors that can be taken to be exogenously given in the short run. Empirical literature on the determinants of FDI is inconclusive ( though extensive) and indicates a range of factors that is too broad to be conveniently tackled in a simple model.

Regarding FPI, two models are presented. Each incorporates expectational factors but the forms are different. In the first expectations are taken to be regressive, whereas in the second the hypothesis of perfect foresight is used. Institutional constraints on asset holding are also different in the two models. While the first model is static, dynamic elements are introduced in the second one. To simplify exposition the producer price index $\mathrm{P}$ is used to deflate nominal balances, so that the money market is independent of the exchange rate.

The home country (India) has three assets - stock, bond and money, which are perfect substitutes for the home investor who does not buy any foreign assets. The foreign investor can purchase stock in India but is debarred from purchasing Indian bonds. This is actually 
10

faithful to the situation in India where there are strong restrictions on the holding of government bonds by foreign institutional investors. For simplicity it is assumed that the foreign investor's choice is restricted between his home stock and Indian stock. The return on the home stock ( of the foreigner) is exogenously given.

There is no uncertainty anywhere in the system and expected inflation is zero.

\section{Model A ( regressive expectation)}

Let $\mathrm{q}$ denote the real value of the stock market in the home country. Domestic demand, either through consumption or investment or both, is taken to be positively related to q. (Blanchard,1981). The value of stock held by the home investor is $\mathrm{q}_{1}$ and that of stock held by the foreigner is $\mathrm{q}_{2}$. Thus, $\mathrm{q}=\mathrm{q}_{1}+\mathrm{q}_{2}$. The dividend or yield on stock to the home investor is $\left(\mathrm{q}_{1} / \mathrm{q}\right) \pi$ and that to the foreign investor is $\left(\mathrm{q}_{2} / \mathrm{q}\right) \pi$, where $\pi$ is the flow of profit in the home country.

The rate of return on stock consists of yield per unit of stock plus expected capital gain. Let us denote the expected capital gains on $\mathrm{q}_{1}$ and $\mathrm{q}_{2}$ by $\mathrm{Z}$ and $\mathrm{Z}$ ' respectively.

The expectation functions are assumed to be of the following type:

$$
z=\frac{a Y}{q}, z^{\prime}=\frac{c Y}{q}
$$

This reflects regressive expectation. As q increases capital gains expected by both the home and the foreign investors decline. The direct relationship with $\mathrm{Y}$ is posited for analytical convenience. We assume $(c>a)$ because the opposite case gives undesirable comparative statics result. The relevant equations are:

(4) $\pi / q+a Y / q=r$

(5) $\mathrm{r}=\mathrm{kY}-\mathrm{gM}$

(6) $\pi / \mathrm{q}+\mathrm{cY} / \mathrm{q}=\rho$

(7) $\mathrm{sY}=\mathrm{aq}+\mathrm{I}_{0}-\mathrm{ir}+\mathrm{NX}$

(8) $\mathrm{NX}=\mathrm{X}_{0}-\mathrm{mY}$

(9) $\mathrm{NX}+\mathrm{NCI}=0$

Equation (4) is the arbitrage condition of the home investor between stock and bond, (6) is the foreign investor's arbitrage condition between Indian stock and his home stock which yields a given return of $\rho$. Equation (7) is the new IS relation which differs from the old one in that the link between the stock market and aggregate demand is introduced through the additional term aq $(\mathrm{a}>0)$. In (8), the influence of the exchange rate on NX is suppressed. The exchange rate is not considered as a variable in this model.

Manipulation of (4), (5) and (6) yields:

$$
q=\frac{(c-a) Y}{\rho-k Y+g M}
$$


This is the QY curve in Figure 2. Equations (7) and (8) give the YY line. Initial equilibrium is at $E_{1}$. The value of NCI is determined from (9), once $\mathrm{Y}$ is known. After a rise in $\rho$, the stock return in the foreign country, QY shifts down and both $\mathrm{Y}$ and $\mathrm{q}$ have lower values in the new equilibrium at $\mathrm{E}_{2}$. Lower $\mathrm{Y}$ goes with a lower NCI from (8) and (9). The logic is that in order to restore (6) a higher $\rho$ causes $q_{2}$ to fall at the initial value of $Y$. The resulting fall in q pulls $\mathrm{Y}$ down by depressing aggregate demand.

\section{Model B ( perfect foresight)}

In this exercise the role of the exchange rate in influencing net exports is restored, so that $\mathrm{NX}$ is represented once again by Equation (iii) of Section 2. In conjunction with (iii) and (v) aggregate demand is given by:

$$
\begin{aligned}
\mathrm{D} & =\mathrm{aq}+\mathrm{cY}+\mathrm{I}_{0}-\mathrm{i}(\mathrm{kY}-\mathrm{gM})+\mathrm{X}_{0}+\mathrm{he}-\mathrm{mY} \\
& =\mathrm{aq}+(\mathrm{c}-\mathrm{ik}-\mathrm{m}) \mathrm{Y}+\mathrm{I}_{0}+\mathrm{X}_{0}
\end{aligned}
$$

The rate of change of $\mathrm{Y}$ is assumed to be proportional to excess demand (D - Y). Profit $\pi$ is taken to be positively related to Y. Indian stocks and the foreign investor's home stock are no longer perfect substitutes to the foreign investor. NCI into India is positively related to the differential between the return on Indian stock and that on foreign stock. To the Indian investor home stock, bond and money remain perfect substitutes. The equations are:

(10) $\pi / \mathrm{q}+\mathrm{Z}=\mathrm{r}$

(11) $\mathrm{r}=\mathrm{kY}-\mathrm{gM}$

(12) $\pi=\alpha Y+\beta$

(13) $\mathrm{NCI}=\mathrm{F}_{0}+\mathrm{f}(\pi / \mathrm{q}+\mathrm{Z} '-\rho)$

(14) $\dot{Y}=\sigma(D-Y)$

(15) $Z=Z_{\mathrm{a}}, Z^{\prime}=Z^{\prime}{ }_{\mathrm{a}}$

(16) $\mathrm{NX}+\mathrm{NCI}=0$

Equation (15) reflects the assumption of perfect foresight. Capital gains expected by Indian and foreign investors ( $Z$ and $Z^{\prime}$ ) are equal to the actual gains $\left(Z_{a}\right.$ and $Z_{a}^{\prime}$ ). In steady state, moreover, we have:

(17) $\dot{Y}=0$

(18) $Z_{a}=Z_{a}^{\prime}=0$

Equations (10),(12),(15) and (18) give us:

$$
q=\frac{\alpha Y+\beta}{k Y-g M}
$$


This is the negatively sloped QY curve in Figure 3. Manipulation of (13),(14),(15) and (16) yields the YY curve :

(20) $q=\frac{s+(i+f) k}{a} Y-\frac{I-F+(i+f) g M}{a}$

The initial steady state equilibrium values of $Y$ and $q$ are given by point $E_{1}$. After an increase in $\mathrm{F}$, autonomous PFI, the equilibrium moves to $\mathrm{E}_{2}$, where $\mathrm{Y}$ is lower and $\mathrm{q}$ is higher. Equation (17) can then be used to show that e must be lower ( currency appreciation). Since $\mathrm{Y}$ is lower, the interest rate is lower. This will have a positive effect on investment. The results here for $\mathrm{Y}, \mathrm{r}$ and e are similar to those obtained in Section 2.

\section{Concluding remarks}

Using a simple Keynesian framework we have demonstrated certain results about the possible impact of greater capital inflow on national income, investment and the exchange rate of an economy open to trade in both the current and capital accounts. The analysis realistically captures many features of the Indian economy in current years.

The model can be extended to include FDI in special economic zones ( SEZ) or free trade zones (FTZ).Although the literature in this field is fairly extensive, rigorous analysis of the full macroeconomic impact of policy decisions with regard to such areas would be a desirable addition.

The analysis of the paper is mostly static in nature, with a little bit of dynamics introduced in the final section. Obviously, there is much room for further research here. The assumption of no uncertainty also needs to be relaxed.

\section{References}

Blanchard, O., 1981, Output, the stock market and interest rates, American Economic Review, March.

Krugman, P, 2000, How complicated does the model have to be?, Oxford Review of Economic Policy, December.

Kumar, N, 2000, Mergers and acquisitions by MNEs : patterns and implications, Economic and Political Weekly, 5 August.

Rakshit, M, 2003, External capital flows and foreign exchange reserves, Money and Finance, April-September. 


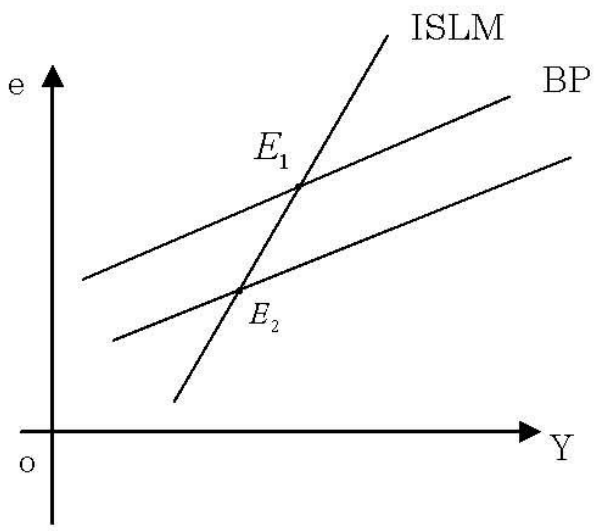

Figure 1: Rise in Capital Inflow

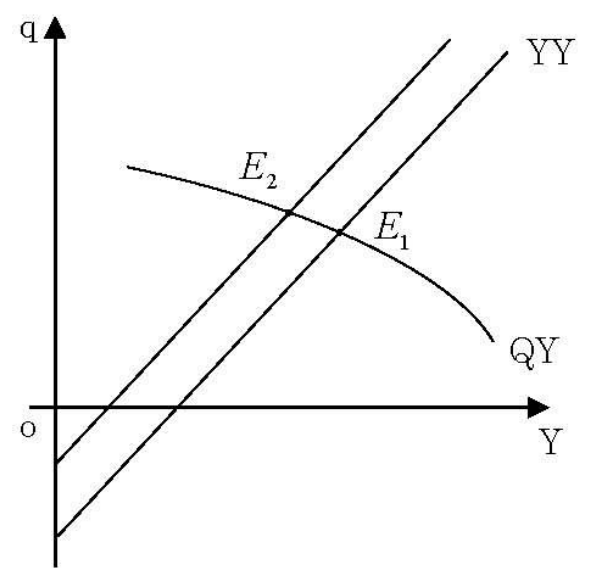

Figure 3: Rise in Capital Inflow

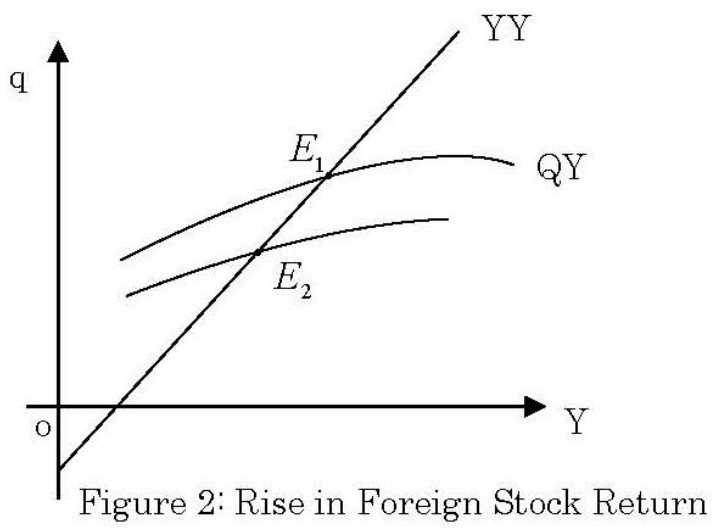

Figure 2: Rise in Foreign Stock Return 